\title{
CsoR regulates the copper efflux operon copZA in Bacillus subtilis
}

\author{
Gregory T. Smaldone and John D. Helmann \\ Department of Microbiology, Cornell University, Ithaca, NY 14853-8101, USA
}

Correspondence

John D. Helmann

jdh9@cornell.edu

Received 16 July 2007

Revised 20 August 2007

Accepted 21 August 2007
The adaptation of Bacillus subtilis to elevated levels of copper ions requires the copper-inducible copZA operon encoding a copper chaperone and efflux ATPase. Here we identify CsoR (formerly YvgZ) as the copper-sensing repressor that regulates the copZA operon. CsoR binds with high affinity to an operator site overlapping the $\operatorname{cop} Z A$ promoter and its binding is specifically inhibited by copper salts. As previously described, the YhdQ (CueR) protein also binds to the copZA regulatory region, but genetic experiments indicate that this protein is not responsible for the copper-dependent regulation of this operon.

\section{INTRODUCTION}

Metals are essential cofactors for many enzymic reactions within the cell. Yet, at high concentrations, many metals become toxic. Toxicity can arise from metal ions binding inappropriately to metal-binding sites in enzymes, thereby inhibiting activity, or by the generation of reactive oxygen species that can damage the genetic, enzymic and structural components of the cell (Imlay, 2002; Touati, 2000). Thus, it is vitally important for the cell to closely regulate metal concentrations within the cytoplasm. When limited for metal ions, many bacteria express high-affinity uptake systems. Conversely, when metals are in excess the cell will often express specific efflux systems or metal-storage proteins. The regulated expression of metal homeostasis mechanisms, including both uptake and efflux systems, is controlled by metalloregulatory proteins that sense metal availability within the cytosol.

Copper is an essential element for Bacillus subtilis aerobic respiration because it is a cofactor for haem-copper oxidases, the terminal enzymes in the respiratory pathway (Mattatall et al., 2000). The pathways responsible for the uptake of copper are not yet defined, but copper present in the cytosol appears to be tightly chaperoned. The Sco chaperone characterized in yeast, humans and bacteria (YpmQ in B. subtilis) mediates the insertion of copper into the $\mathrm{Cu}_{\mathrm{A}}$ copper centre of cytochrome $c$ oxidase (Mattatall et al., 2000). It has also recently been suggested that Sco may play a role in the insertion of copper into the $\mathrm{Cu}_{\mathrm{B}}$ centres of the haem-copper oxidases, and may play a more general role as a copper chaperone for other metalloproteins (Banci et al., 2007).

When copper is present in excess, a specific efflux system encoded by the copZA operon is induced (Gaballa \&

Abbreviation: EMSA, electrophoretic mobility shift assay.
Helmann, 2003). Strong induction of copZA was noted in the presence of copper salts, but not other metals tested, and the CopZA system was shown to be required for resistance to high levels of copper (Gaballa \& Helmann, 2003). CopZ functions as a copper chaperone to deliver copper to CopA, a CPx-type efflux ATPase (Banci et al., 2001; Radford et al., 2003). Structural analyses have allowed visualization of B. subtilis Sco, CopZ and the Nterminal domain of CopA, thereby affording a detailed look at the molecular mechanics of copper homeostasis in this model organism (Balatri et al., 2003; Banci et al., 2001, 2003).

The regulatory proteins controlling the expression of these copper homeostasis proteins are not as well defined. Previously, we identified a MerR-type regulatory protein (YhdQ; previously renamed CueR) as a candidate regulator for the copZA operon (Gaballa et al., 2003). Here, we provide evidence that this assignment was incorrect: although YhdQ does bind to the copZA regulatory region $\left(\mathrm{P}_{\text {copZA }}\right)$ in vitro, this binding may not be physiologically relevant. Our previously reported genetic studies linking $y h d Q$ to the copper-dependent induction of $\operatorname{cop} Z A$ were incorrect due to an inadvertent error in strain construction. Here, we present evidence that YvgZ, an orthologue of the recently described copper-sensing metalloregulator CsoR from Mycobacterium tuberculosis (Liu et al., 2007), is the copper-sensing regulator of the $\operatorname{cop} Z A$ operon.

\section{METHODS}

Bacterial strains, media and growth conditions. Bacterial strains used in this study are listed in Table 1. Escherichia coli DH5 $\alpha$ was used for routine DNA cloning (Sambrook et al., 1989). Liquid media were inoculated from overnight pre-culture and incubated at $37^{\circ} \mathrm{C}$ with shaking at 225 r.p.m. Erythromycin $\left(1 \mu \mathrm{g} \mathrm{ml}{ }^{-1}\right)$ and lincomycin $\left(25 \mu \mathrm{g} \mathrm{ml} \mathrm{m}^{-1}\right.$ ) [for MLS (macrolide-lincosamide-streptomycin B) resistance], spectinomycin $\left(100 \mu \mathrm{g} \mathrm{ml}^{-1}\right)$, kanamycin $\left(10 \mu \mathrm{g} \mathrm{ml}^{-1}\right)$, 
Table 1. Bacterial strains and plasmids used in this study

\begin{tabular}{|c|c|c|}
\hline Strain or plasmid & Relevant characteristic(s) & Source or reference \\
\hline \multicolumn{3}{|l|}{ B. subtilis } \\
\hline CU1065 & $\mathrm{W} 168$ att SP $\beta \operatorname{trp} C 2$ & Vander Horn \& Zahler (1992) \\
\hline HB7301 & CU1065 yhdQ::kan & This study \\
\hline HB7350 & CU1065 csoR: :spc & This study \\
\hline HB7351 & CU1065 yhdQ:: kan csoR::spc & This study \\
\hline HB7352 & CU1065 csoR: : spc SP $\beta\left(\mathrm{P}_{\text {copZA-cat-lacZ }}\right)\left(\mathrm{MLS}^{\mathrm{R}} \mathrm{Neo}^{\mathrm{R}}\right)$ & This study \\
\hline HB7353 & CU1065 yhdQ:: kan csoR:: spc SP $\beta\left(\mathrm{P}_{\text {copZA }}\right.$-cat-lacZ) $\left(\mathrm{MLS}^{\mathrm{R}} \mathrm{Neo}^{\mathrm{R}}\right)$ & This study \\
\hline HB7354 & CU1065 csoR: : spc amyE:: csoR-cat & This study \\
\hline HB7355 & CU1065 yhdQ:: kan csoR::spc amyE::csoR-cat & This study \\
\hline HB7356 & 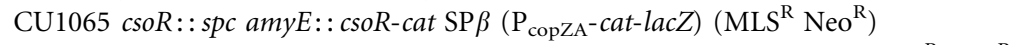 & This study \\
\hline HB7357 & CU1065 yhdQ:: kan csoR:: spc amyE::csoR-cat $\mathrm{SP} \beta\left(\mathrm{P}_{\text {copZA }}\right.$-cat-lacZ $)\left(\mathrm{MLS}^{\mathrm{R}} \mathrm{Neo}^{\mathrm{R}}\right)$ & This study \\
\hline HB7358 & 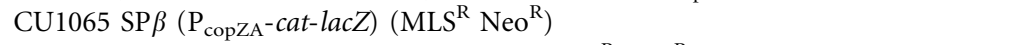 & This study \\
\hline HB7359 & CU1065 yhdQ:: kan SP $\beta\left(\mathrm{P}_{\text {copZA }}\right.$-cat-lacZ) $\left(\mathrm{MLS}^{\mathrm{R}} \mathrm{Neo}^{\mathrm{R}}\right)$ & This study \\
\hline \multicolumn{3}{|c|}{ 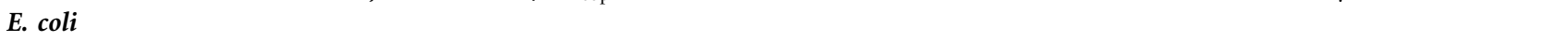 } \\
\hline $\mathrm{DH} 5 \alpha$ & $\begin{array}{l}\phi 80 \Delta(\operatorname{lacZ}) \mathrm{M} 15 \Delta(\operatorname{argF}-l a c) \mathrm{U} 169 \text { endA1 recA1 hsdR17 }\left(\mathrm{r}_{\mathrm{K}}^{-} \mathrm{m}_{\mathrm{K}}^{+}\right) \text {deoR thi-1 supE44 } \\
\text { gyrA96 relA1 }\end{array}$ & Sambrook et al. (1989) \\
\hline BL21 (DE3)(pLysS) & $\mathrm{F}^{-} \operatorname{omp} T h s d S_{\mathrm{B}}\left(\mathrm{r}_{\mathrm{B}}^{-} \mathrm{m}_{\mathrm{B}}^{-}\right) g a l d c m(\mathrm{DE} 3) / \mathrm{pLysS}$ & Novagen \\
\hline HE7307 & BL21 pGS001 & This study \\
\hline HE8248 & BL21 with pET16X containing $y h d Q$ cloned into the $N c o$ I and BamHI sites & Gaballa et al. (2003) \\
\hline \multicolumn{3}{|l|}{ Plasmid } \\
\hline pGS001 & pET16b containing $c s o R$ cloned into the $N c o$ I and BamHI sites & This study \\
\hline
\end{tabular}

neomycin $\left(10 \mu \mathrm{g} \mathrm{ml}^{-1}\right)$ and chloramphenicol $\left(5 \mu \mathrm{g} \mathrm{ml}^{-1}\right)$ were used for the selection of various $B$. subtilis strains. To determine growth in the presence of copper, strains were cultivated overnight in LB, diluted 1:100 in $5 \mathrm{ml} \mathrm{LB}$, and grown to mid-exponential phase $\left(\mathrm{OD}_{600} \sim 0.4\right)$. Three microlitres of cells were inoculated into $197 \mu \mathrm{l}$ $\mathrm{LB}$ containing $\mathrm{CuSO}_{4}$ from 0 to $6 \mathrm{mM}$ in a 100 -well microtitre plate and growth was monitored after overnight growth with shaking at $37^{\circ} \mathrm{C}$ using a BioScreen $\mathrm{C}$ plate reader.

DNA manipulations. Routine molecular biology procedures were performed according to Sambrook et al. (1989). Transformation and specialized SP $\beta$ transduction were performed as described by Cutting \& Vander Horn (1990). Restriction enzymes, DNA ligase and T4 PNK were all used according to the manufacturer's instructions (New England Biolabs).

Strain construction. Null mutants were generated by allelic replacement via a modified long flanking homology PCR protocol (Wach, 1996; Gaballa et al., 2003). The resulting PCR products were purified and introduced by transformation into B. subtilis wild-type strain CU1065 or appropriate mutant strain with appropriate antibiotic selection. Mutants generated in this study are listed in Table 1.

$\boldsymbol{\beta}$-Galactosidase assay. The $\mathrm{P}_{\text {copZA-cat-lacZ operon fusion, carried }}$ on the SP $\beta$ prophage, was introduced by specialized transduction. Overnight cultures were diluted 1:100 in LB liquid medium with or without $0.5 \mathrm{mM} \mathrm{CuSO}_{4}$ and grown to mid-exponential phase. Cells were collected and the expression of $\beta$-galactosidase was measured (modified from Miller, 1972).

Purification of CsoR. The $y v g Z$ ( $c s o R)$ gene was PCR amplified and inserted into the $\mathrm{NcoI}$ and the BamHI sites of the overexpression vector pET16b (Novagen). This was then introduced into E. coli $\mathrm{DH} 5 \alpha$ by transformation. The sequence of the resulting plasmid (pGS001) was verified by DNA sequencing (Cornell Life Sciences Core Laboratories Center) and was introduced into E. coli BL21
(DE3)(pLysS). A single colony was grown overnight in $5 \mathrm{ml} \mathrm{LB}$ containing ampicillin $\left(100 \mu \mathrm{g} \mathrm{ml}^{-1}\right)$. The overnight culture was used to inoculate 1 litre of $\mathrm{LB}$ containing ampicillin $\left(100 \mu \mathrm{g} \mathrm{ml}^{-1}\right)$. Cells were incubated with vigorous shaking until an $\mathrm{OD}_{600}$ of 0.4 (Milton Roy Spectronic 21) was reached, at which point IPTG was added to a final concentration of $4 \mathrm{mM}$, and the cells were allowed to grow an additional $2 \mathrm{~h}$. Cells were recovered by centrifugation, resuspended in buffer A $(20 \mathrm{mM}$ Tris/ $\mathrm{HCl} \mathrm{pH} 8.0,100 \mathrm{mM} \mathrm{NaCl}, 1 \mathrm{mM}$ EDTA, $1 \mathrm{mM}$ DTT, $5 \%, \mathrm{v} / \mathrm{v}$, glycerol), and sonicated. The extract was clarified by centrifugation and then purified by sequential application to heparin-Sepharose, mono-Q ion-exchange and Superdex-200 sizeexclusion columns. Purified protein was stored in Buffer A at $-80{ }^{\circ} \mathrm{C}$ for later use. CsoR purity was determined to be $>95 \%$ by SDS-PAGE with Coomassie staining. YhdQ had been purified during previous studies (Gaballa et al., 2003).

Electrophoretic mobility shift assays (EMSAs). PCR fragments containing the copZA promoter (246 bp) and the control non-specific yoe $B$ promoter (106 bp) were amplified and labelled with $\mathrm{T} 4$ polynucleotide kinase (PNK) and $\left[\gamma_{-}{ }^{32} \mathrm{P}\right] \mathrm{ATP}$. EMSA reactions were carried out in $10 \mu \mathrm{l}$ EMSA buffer $(20 \mathrm{mM}$ Tris/HCl pH 8.0, $50 \mu \mathrm{g}$ BSA ml ${ }^{-1}, 50 \mathrm{mM} \mathrm{NaCl}, 1 \mathrm{mM}$ DTT, $5 \mu \mathrm{g}$ salmon sperm DNA ml ${ }^{-1}$, $5 \%, \mathrm{v} / \mathrm{v}$, glycerol). Increasing concentrations of CsoR and YhdQ were incubated for $10 \mathrm{~min}$ at room temperature with the labelled promoters in both the presence and absence of $10 \mu \mathrm{M} \mathrm{CuSO}_{4}$ (as indicated). DTT was added to the reaction to reduce $\mathrm{Cu}(\mathrm{II})$ to $\mathrm{Cu}(\mathrm{I})$ (Banci et al., 2001). The copZA promoter was digested with BtsI and the control non-specific ytiA promoter with EcoRI where indicated. All samples were loaded onto a $6 \%$ polyacrylamide gel and electrophoresed for $1 \mathrm{~h}$ at $90 \mathrm{~V}$ in $45 \mathrm{mM}$ Tris/borate buffer (without EDTA), pH 8.0. The gel was dried and imaged on a Storm 840 PhosphorImager scanner (Molecular Dynamics) after overnight exposure of a PhosphorImager screen.

DNase I footprinting. Oligonucleotide primers labelled with T4 PNK and $\left[\gamma_{-}{ }^{32} \mathrm{P}\right] \mathrm{ATP}$ were used to generate a $246 \mathrm{bp} \mathrm{P}_{\text {copZA }}$ fragment. PCR with the labelled forward or reverse primer (and a second, 
unlabelled primer) was used to generate labelled fragments. Footprinting was carried out in $50 \mu$ EMSA buffer. CsoR was added in increasing amounts to the top- or bottom-strand end-labelled PCR product and incubated at room temperature for $20 \mathrm{~min}$. After this binding incubation, $53 \mu \mathrm{l}$ DNase I reaction mixture (0.06 units DNase I $\mu \mathrm{l}^{-1}, 5 \mathrm{mM} \mathrm{CaCl}_{2}, 10 \mathrm{mM} \mathrm{MgCl}$ ) was added to digest the labelled DNA. Digestion was performed at room temperature for $2 \mathrm{~min}$ and stopped by precipitation of the DNA with $645 \mu \mathrm{l}-20{ }^{\circ} \mathrm{C}$ absolute ethanol, $50 \mu \mathrm{l} 3 \mathrm{M}$ sodium acetate and $5 \mu \mathrm{l} 1 \mathrm{mg}$ yeast carrier RNA ml $\mathrm{m}^{-1}$ at $-20{ }^{\circ} \mathrm{C}$ for $20 \mathrm{~min}$. DNA was collected by centrifugation, washed with cold $70 \%$ ethanol, and the dried pellets were dissolved in $7.5 \mu \mathrm{l}$ formamide loading buffer. Samples were incubated at $90{ }^{\circ} \mathrm{C}$ for 3 min before loading. The $\mathrm{G}+\mathrm{A}$ ladder was generated by adding $1 \mu \mathrm{l}$ labelled promoter to $3 \mu \mathrm{l}$ formamide loading buffer with $1 \%$ formic acid added; the reaction was incubated at $90{ }^{\circ} \mathrm{C}$ for $20 \mathrm{~min}$. Then $3 \mu \mathrm{l} \mathrm{G}+\mathrm{A}$ ladder and $7.5 \mu \mathrm{l}$ of the DNase I footprinting reactions were loaded onto a $6 \%$ polyacrylamide sequencing gel with $6 \mathrm{M}$ urea pre-run in $0.5 \times \mathrm{TBE}$ electrophoresis buffer at $1500 \mathrm{~V}$ for $40 \mathrm{~min}$. The gel was run for $1 \mathrm{~h}$ at $1500 \mathrm{~V}$, dried, and imaged on a Storm 840 PhosphorImager scanner (Molecular Dynamics) after overnight exposure of a PhosphorImager screen.

\section{RESULTS AND DISCUSSION}

\section{CsoR negatively regulates the copZA operon}

The copZA operon is situated downstream of a candidate $\sigma^{\mathrm{A}}$ promoter sequence with an overlapping GC-rich pseudo-inverted repeat (Fig. 1). As noted previously, $\mathrm{P}_{\text {copZA }}$ has features similar to promoters regulated by MerR family transcription factors, including a longer than average spacer sequence and an inverted repeat element in the spacer region similar to known MerR-binding sites. These observations led us to investigate the role of MerRlike proteins as candidate regulators for $\operatorname{cop} Z A$. Previously, we reported that a disruption of $y h d Q$ resulted in reduced expression levels of a $\mathrm{P}_{\text {copZA }}$ reporter fusion relative to levels in a wild-type background. Together with biochemical studies that demonstrated binding of YhdQ to $\mathrm{P}_{\text {copZA }}$ we concluded that this protein mediated copper induction of copZA and we proposed to rename $y h d Q$ as cueR (Gaballa et al., 2003). This assignment was supported by the limited similarity (17\% identity) between B. subtilis YhdQ and E. coli CueR (Outten et al., 2000; Stoyanov et al., 2001). However, we demonstrate here that $y h d Q$ is not involved in the copper-dependent regulation of copper efflux functions, and we will henceforth refer to this gene as $y h d Q$ (as presently annotated in the SubtiList database; Moszer et al., 1995) rather than cueR.

In the course of follow-up studies to determine the structural features of YhdQ required for copper sensing, we were unable to reproduce the previously observed defects in induction of the $\mathrm{P}_{\text {copZA }}$ reporter fusion in strains lacking YhdQ. Analysis of the original strains revealed an error in strain construction: in the course of introducing reporter fusions by phage transduction, the wrong promoter fusion had been introduced into the $y h d Q$ null background. In our newly constructed strains, a yhdQ null mutation did not affect copper inducibility of $\mathrm{P}_{\text {copZA }}$ (Fig. 2a).

Concurrent with this discovery, a report appeared describing a new family of copper-sensing regulatory proteins designated CsoR (Liu et al., 2007). The prototype for this family of metalloregulatory proteins is the $M$. tuberculosis CsoR protein, which functions as a $\mathrm{Cu}(\mathrm{I})$ selective repressor protein and regulates expression of copper efflux systems. Giedroc and colleagues noted that apparent CsoR orthologues are present in many bacteria and they speculated that these might also play a role in regulating copper homeostasis (Liu et al., 2007). The predicted CsoR orthologue in B. subtilis is encoded by the $y v g Z$ gene, which is located immediately upstream of the copZA operon (Fig. 1). YvgZ of B. subtilis shares $33 \%$ amino acid identity with $M$. tuberculosis CsoR, consistent with a similar functional role. More importantly, the

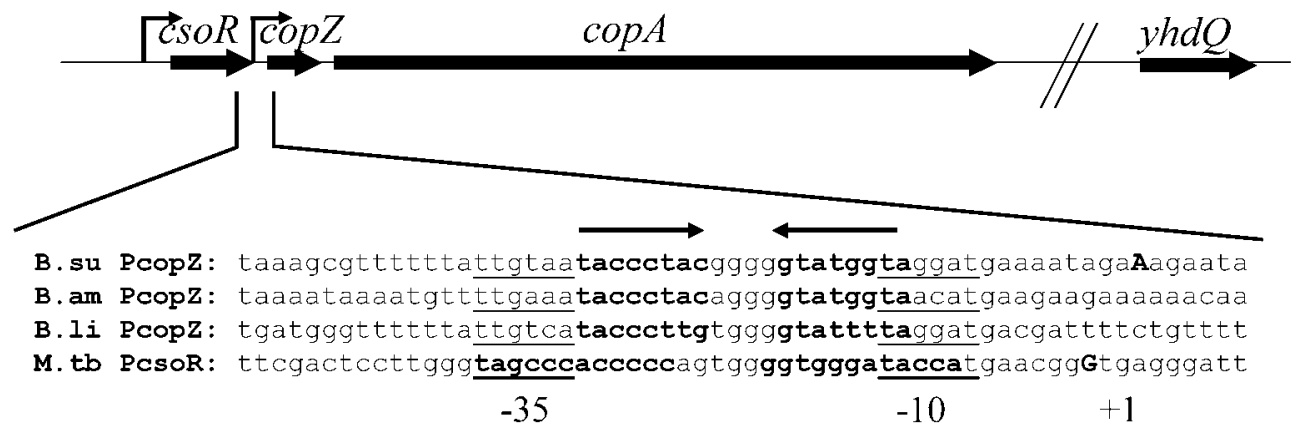

Fig. 1. Schematic representation of the $\operatorname{cso} R-\operatorname{cop} Z A$ locus. $c s o R(y v g Z)$ is located immediately upstream of the copZA operon and is transcribed from its own promoter. The $y h d Q$ (cueR) gene is distant from the copZA operon. The promoter region between $c s o R$ and $\operatorname{cop} Z$ has been expanded to illustrate the sequence alignment of $B$. subtilis (B.su), B. amyloliquefaciens (B.am), B. licheniformis (B.li), and M. tuberculosis (M.tb). Conserved -35 and -10 promoter elements are underlined. Bold letters represent the conserved GC-rich pseudo-inverted repeat. The identified +1 sites of transcription (Gaballa \& Helmann, 2003; Liu et al., 2007) are designated by capital letters. 


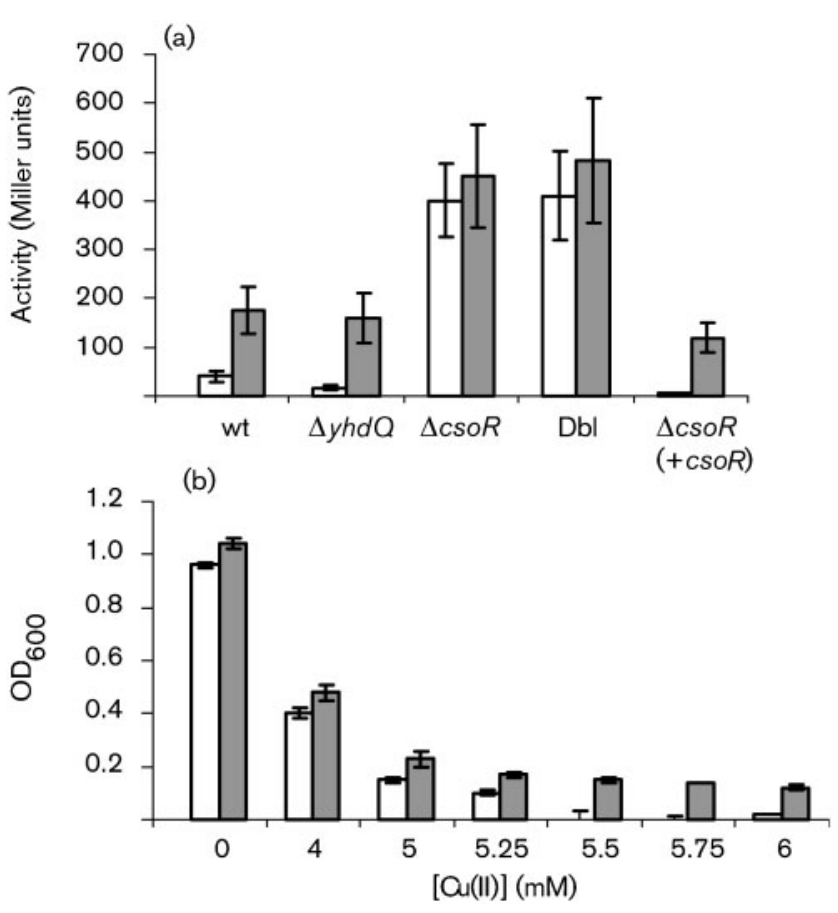

Fig. 2. Expression of $P_{\text {copzA }}$ is affected in a csoR null background. (a) Expression of $\mathrm{P}_{\text {copZA-cat-lacZ promoter fusion in different null }}$ backgrounds with (grey bars) and without (white bars) $\mathrm{CuSO}_{4}$ added to a final concentration of $0.5 \mathrm{mM}$ was measured using $\beta$ galactosidase assays. Dbl, $\Delta c s o R \Delta y h d Q$ double mutant; $\Delta c s o R$ $(+\operatorname{cso} R)$, csoR null mutant complemented ectopically with csoR. Results presented are the means \pm SD of three experiments where the total $n=7$. (b) Growth yield for wild-type (CU1065; white bars) and its isogenic csoR null mutant (grey bars) after overnight growth in medium either lacking (0) or supplemented with $\mathrm{CuSO}_{4}$ at the indicated concentration.

ligand-coordinating residues shown to be essential for copper-sensing in $M$. tuberculosis CsoR are strictly conserved in B. subtilis (C45, H70 and C74). Other conserved residues include $\mathrm{Y} 44$ and $\mathrm{E} 90$, which have been implicated in the allosteric modulation of the DNAbinding domain in response to bound copper (Liu et al., 2007). Previous studies had demonstrated that $y v g Z$ is not co-transcribed with $\operatorname{cop} Z A$, nor is it copper regulated (Gaballa \& Helmann, 2003). We demonstrate that $y v g Z$ is required for the copper-dependent regulation of the $\operatorname{cop} Z A$ efflux operon. Hence, we rename this gene $c s o R$, to be consistent with the M. tuberculosis nomenclature (Liu et al., 2007).

To determine whether CsoR regulates the copZA operon and to investigate the role of YhdQ, a series of allelic replacement mutations were constructed (Table 1) and tested for their effect on copper induction of a $\mathrm{P}_{\text {copZA }}{ }^{-c a t-}$ lac $Z$ promoter fusion (Fig. 2a). In the $c s o R$ null mutant the copZA promoter was expressed constitutively (Fig. 2a). Complementation of the mutant strain with an ectopically integrated copy of the $c s o R$ gene restored wild-type (a)

[CsoR], nM $\quad 0 \quad 10 \quad 25 \quad 37.550 \quad 62.575 \quad 87.5100100$

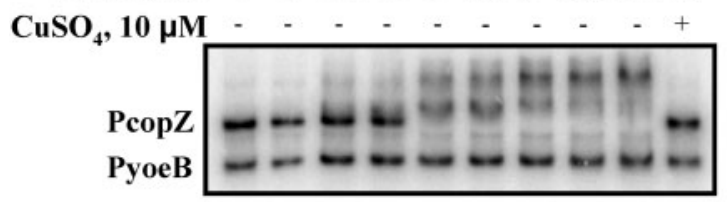

(b)

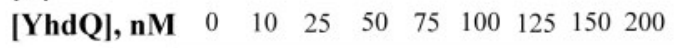

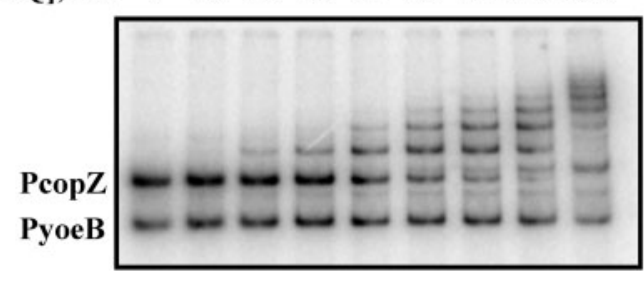

(c)

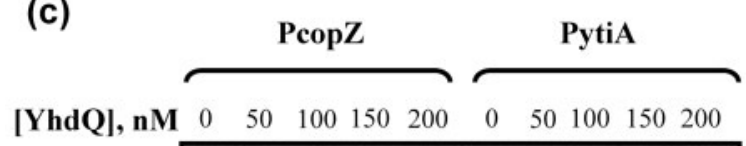

Fig. 3. EMSAs. (a) CsoR EMSA was carried out with increasing amounts of protein and a constant amount of both specific copZA promoter and non-specific yoe $B$ promoter; $10 \mu \mathrm{M} \mathrm{CuSO}_{4}$ in the presence of $1 \mathrm{mM}$ DTT was added to the last lane to test the effects of copper on DNA-binding activity. (b) YhdQ EMSA with increasing amounts of protein and a constant amount of both specific copZA promoter and non-specific copper uninduced yoeB promoter. (c) YhdQ EMSA carried out with both specific copZA promoter and non-specific ytiA promoter. Both promoters were digested with either Btsl or EcoRl to generate a promoter specific fragment (upper band in ' $O$ ' lane) and a non-specific fragment (lower band in ' 0 ' lane).

regulation. These results suggest that CsoR functions as a

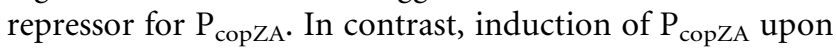
exposure to copper was unaffected in a $y h d Q$ null mutant. Since YhdQ had been previously shown to bind the copZA regulatory region (Gaballa et al., 2003), we considered the possibility that both proteins might exert a regulatory influence over copZA expression. However, the $c s o R$ yhdQ double mutant was indistinguishable from the $c s o R$ single mutant (Fig. 2a).

Since a $c s o R$ null mutant expresses copper efflux functions constitutively, we hypothesized that this strain should have 
a higher tolerance for copper shock. This expectation is supported by the observation that the null mutant has a slightly enhanced ability to grow relative to wild-type when diluted into medium containing high levels of copper (Fig. 2b); this is most apparent at concentrations between 5 and $6 \mathrm{mM}$ copper. This effect is rather subtle, consistent with the fact that the $\operatorname{cop} Z A$ operon is probably induced even in the wild-type strain under these conditions. In contrast, a $\operatorname{cop} A$ null mutant is unable to grow in medium containing $2 \mathrm{mM}$ copper (Gaballa \& Helmann, 2003).

\section{CsoR specifically binds $P_{\text {copza }}$ in the absence, but not the presence, of copper ions}

EMSA was used to determine if CsoR is acting as a coppersensing repressor. CsoR bound with high affinity $\left(K_{\mathrm{d}}\right.$ $\sim 50 \mathrm{nM})$ to $\mathrm{P}_{\text {copZA }}$, but not to the non-specific control fragment $(y o e B)$, and this binding was eliminated in the presence of $10 \mu \mathrm{M} \mathrm{CuSO}_{4}$ and $1 \mathrm{mM}$ DTT (Fig. 3a). Under these conditions, DTT is known to reduce $\mathrm{Cu}(\mathrm{II})$ to $\mathrm{Cu}(\mathrm{I})$ (Banci et al., 2001), the presumed inducer by analogy with M. tuberculosis CsoR (Liu et al., 2007). In parallel EMSA reactions with YhdQ, significant binding was detected to

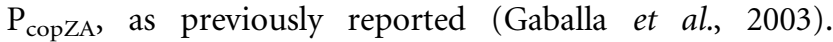
Moreover, this binding appeared to be of higher affinity than that for the non-specific control fragment (yoeB), suggesting that there is some specificity for the copZA promoter DNA fragment. However, the formation of several different mobility complexes (Fig. 3b) suggests that there may be multiple YhdQ oligomers bound to this DNA fragment. To further investigate the DNA-binding properties of YhdQ, EMSAs were conducted with two additional control DNA fragments: the copZA promoter region digested with BtsI (to generate two fragments, one of which lacks the proposed specific binding site) and the noncopper-regulated $y t i A$ promoter digested with EcoRI. Both fragments produced a ladder of shifted complexes (Fig. 3c). Taken together, these results suggest that YhdQ binds to DNA in a relatively non-specific manner while CsoR binds specifically to the $\mathrm{P}_{\text {copz }}$ region with high affinity.

\section{CsoR binds to an inverted repeat overlapping the promoter of cOpZA}

Using DNase I footprinting, CsoR was found to protect a $25 \mathrm{nt}$ region of the top strand, overlapping the copZA promoter. In agreement with the EMSA experiments, the protection of the promoter region is lifted once copper is supplied to the reaction (Fig. 4). This result is consistent with the role of $\mathrm{CsoR}$ as a repressor. Furthermore, CsoR (a)

[CsoR], nM 吉。

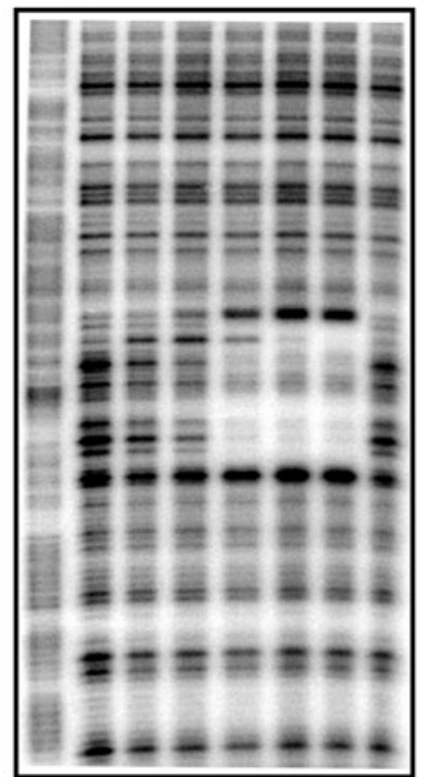

(b)

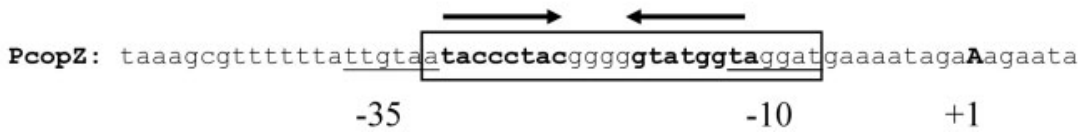

Fig. 4. The CsoR-binding site overlaps the copZA promoter. (a) DNase I footprinting of the top stand of $P_{\text {copzA }}$ with increasing amounts of CsoR. The last lane contains $10 \mu \mathrm{M} \mathrm{CuSO}$ in the presence of $1 \mathrm{mM} \mathrm{DTT}$. The $\mathrm{G}+\mathrm{A}$ ladder was run as a standard; it was calibrated to a dideoxy chain-termination sequencing reaction (data not shown). (b) Schematic of the $B$. subtilis $\operatorname{copZA}$ promoter. The -10 and -35 elements are underlined, the GC-rich pseudo-inverted repeat is in bold, and the protected region as determined by the DNase I footprinting is boxed. 
protects the same general DNA region on the bottom strand over the same range of protein concentrations (data not shown). It is interesting to note that this operator region in B. subtilis and its close relatives shares similarity with the M. tuberculosis csoR binding site (Fig. 1). This GCrich pseudo-inverted repeat probably mediates CsoR binding and regulation.

\section{Conclusions}

In this study, we have identified the regulator of the $\operatorname{cop} Z A$ operon as CsoR (formerly YvgZ). We had previously assigned this role to YhdQ (CueR), a MerR homologue, proposed to function as an activator of copper efflux (Gaballa et al., 2003). This assignment was supported by the observed binding of YhdQ to the copZA regulatory region, the loss of $\mathrm{P}_{\text {copZA }}$ induction in a strain carrying a $y$ hdQ mutation, and weak similarity in protein sequence ( $17 \%$ identity) between B. subtilis YhdQ and the CueR regulator of copper efflux gene expression in E. coli. However, due to an error in strain construction, the previous genetic experiments were incorrect and we now report that there is no effect on copper-dependent regulation at the copZA promoter in a $y h d Q$ mutant strain. Consistent with our previous findings (Gaballa et al., 2003), YhdQ does bind with high affinity to the copZA promoter region, but it also binds to several other promoter regions, suggesting that this binding is relatively non-specific and unlikely to be physiologically relevant. Our current results support a model for CsoR as the sole repressor of the copZA operon in $B$. subtilis that is responsible for the previously characterized, copperspecific induction of this efflux system (Gaballa \& Helmann, 2003).

\section{ACKNOWLEDGEMENTS}

We thank Dr Ahmed Gaballa for helpful comments and Dr Jin-Won Lee for purified CueR protein. This work was supported by a grant from the National Institutes of Health (GM59323).

\section{REFERENCES}

Balatri, E., Banci, L., Bertini, I., Cantini, F. \& Ciofi-Baffoni, S. (2003). Solution structure of Scol: a thioredoxin-like protein involved in cytochrome $c$ oxidase assembly. Structure 11, 1431-1443.

Banci, L., Bertini, I., Conte, R. D., Markey, J. \& Ruiz-Duenas, F. J. (2001). Copper trafficking: the solution structure of Bacillus subtilis CopZ. Biochemistry 40, 15660-15668.
Banci, L., Bertini, I., Ciofi-Baffoni, S., Gonnelli, L. \& Su, X. (2003). Structural basis for the function of the N-terminal domain of the ATPase CopA from Bacillus subtilis. J Biol Chem 278, 50506-50513.

Banci, L., Bertini, I., Cavallaro, G. \& Rosato, A. (2007). The functions of Sco proteins from genome-based analysis. J Proteome Res 6, $1568-1579$.

Cutting, S. \& Vander Horn, P. B. (1990). Molecular Biological Methods for Bacillus. Chichester: Wiley.

Gaballa, A. \& Helmann, J. D. (2003). Bacillus subtilis CPx-type ATPases: characterization of $\mathrm{Cd}, \mathrm{Zn}$, Co, and $\mathrm{Cu}$ efflux systems. Biometals 16, 497-505.

Gaballa, A., Cao, M. \& Helmann, J. D. (2003). Two MerR homologues that affect copper induction of the Bacillus subtilis copZA operon. Microbiology 149, 3413-3421.

Imlay, J. A. (2002). How oxygen damages microbes: oxygen tolerance and obligate anaerobiosis. Adv Microb Physiol 46, 111-153.

Liu, T., Ramesh, A., Ma, Z., Ward, S. K., Zhang, L., George, G. N., Talaat, A. M., Sacchettini, J. C. \& Giedroc, D. P. (2007). CsoR is a novel Mycobacterium tuberculosis copper-sensing transcriptional regulator. Nat Chem Biol 3, 60-68.

Mattatall, N. R., Jazairi, J. \& Hill, B. C. (2000). Characterization of $\mathrm{YpmQ}$, an accessory protein required for the expression of cytochrome c oxidase in Bacillus subtilis. J Biol Chem 275, 28802-28809.

Miller, J. H. (1972). Assay of $\beta$-galactosidase. In Experiments in Molecular Genetics, pp. 352-355. Cold Spring Harbor, NY: Cold Spring Harbor Laboratory.

Moszer, I., Glaser, P. \& Danchin, A. (1995). SubtiList: a relational database for the Bacillus subtilis genome. Microbiology 141, 261-268.

Outten, F. W., Outten, C. E., Hale, J. \& O'Halloran, T. V. (2000). Transcriptional activation of an Escherichia coli copper efflux regulon by the chromosomal MerR homologue, CueR. J Biol Chem 275, 31024-31029.

Radford, D. S., Kihlken, M. A., Borrelly, G. P., Harwood, C. R., Le Brun, N. E. \& Cavet, J. S. (2003). CopZ from Bacillus subtilis interacts in vivo with a copper exporting CPx-type ATPase CopA. FEMS Microbiol Lett 220, 105-112.

Sambrook, J., Fritsch, E. F. \& Maniatis, T. (1989). Molecular Cloning: a Laboratory Manual, 2nd edn. Cold Spring Harbor, NY: Cold Spring Harbor Laboratory.

Stoyanov, J. V., Hobman, J. L. \& Brown, N. L. (2001). CueR (YbbI) of Escherichia coli is a MerR family regulator controlling expression of the copper exporter CopA. Mol Microbiol 39, 502-511.

Touati, D. (2000). Iron and oxidative stress in bacteria. Arch Biochem Biophys 373, 1-6.

Vander Horn, P. B. \& Zahler, S. A. (1992). Cloning and nucleotide sequence of the leucyl-tRNA synthetase gene of Bacillus subtilis. J Bacteriol 174, 3928-3935.

Wach, A. (1996). PCR-synthesis of marker cassettes with long flanking homology regions for gene disruptions in S. cerevisiae. Yeast 12, 259-265.

Edited by: J.-H. Roe 